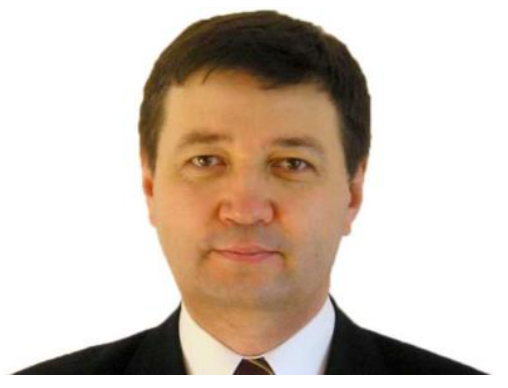

\section{Renewable Energy Sources and the New Paradigm in Energy Engineering}

\author{
Prof. Eden MAMUT, Director \\ Institute for Nanotechnologies \& Alternative Energy Sources \\ "Ovidius" University of Constanta, Romania \\ Email: eden.mamut@et-is.eu
}

After centuries of scientific, industrial and technological achievements the current paradigm in energy engineering may be defined as the complex set of knowledge, technologies, policies but even individual and community attitudes aiming to assure at the level of each energy end-user the required quantity and quality of energy, at minimum price and with minimal impact on the environment on a life cycle reasoning from production to final use.

In 2012, I had the chance to participate at the UN Conference on Sustainable Development organized at Rio de Janeiro, the so called "Rio + 20" Conference, as a member of the Official Delegation of Romania and at the same time representing the UN Academic Impact Initiative. On that position, I had the possibility to join many sessions of the Conference and to follow also the process of negotiations for the text of the Final Declaration of the Conference. Passing from one session to another, there were several aspects that were confusing me.

One of them was a declaration of the representative of a large company from Brazil, mentioning that his country has a huge stockpile of biomass and if it shall be used as bioenergy resource, it is plenty to assure the welfare of that country. The confusion for me was if a Global Ecosystem as the Amazonian Forest, could be considered an asset to be exploited at the discretion of some local groups of interest. It is well known, that the complexity of the factors that are interlinked with the biomass in different ecosystems it is not yet very clear even for small ecosystems. The current attempts to develop detailed Multiscale and Multiphysics models for parts of the deltas of Mississippi River in the US or Danube Delta in Europe are in some initial stages and there will be needed decades of scientific research for developing comprehensive models for global macro-ecosystems like the Nile or the Amazonian.

Unfortunately, at present, the quotas for exploiting resources as forest wood or reed in wetlands or Deltas in many parts of the World are established without any scientific background. But many published reports reveled that even the simple question: "what is the percentage of straw that is yielded from a hectare of wheat that may be used for energy or industrial purpose?" has the answer "depends on many factors". With interdisciplinary and crossdisciplinary approaches, reliable tools and methods may be developed to strengthen the methodologies as "ecosystem services" and this movement has to be further multiplied in order to become a norm.

As an example, in the Black Sea Region we have developed an Alliance of Space research centers to aggregate satellite data with advanced computing codes in order to evaluate the potential of exploitation of renewable energy resources as biomass, solar, wind or water currents and similar initiatives are also in many other regions of the World. The most important aspect that we learn, is that renewable energy sources have no borders and even the very rudimental tools that we have yet, allow us to understand that there are situations when between a large storm in the Sahara desert and the yield of biomass from the Amazonian Delta may be many interlinked and influencing factors.

The major disappointment at the end of "Rio + 20" Conference held in 2012, was that the final resolution was blocked by the group of the Non-Aligned Countries on the argument that the developed countries have already a set of technologies on the shelf and would like to impose them to the developing countries. Such an argument is very often promoted in different Conferences or meetings organized at certain levels. As an example, in Romania, the scientific research activities on wind energy have started in 1974 as a National Program for Alternative Energy Sources. Over many decades, there were spent significant amounts of funds for developing original solutions and technologies. Unfortunately, the scientific research achievements have not been transferred to industry and business. As a consequence, when Romania joined the EU in 2007 and specific subsidy programs have been initiated to promote renewable energy sources, all investment projects on wind farms have been developed with technologies from the developed countries. It took us several years to understand the very important connection between the scientific research, innovation and competitiveness at regional and global scales. 
At present, at the Institute for Nanotechnologies and Alternative Energy Sources, at "Ovidius" University of Constanta, we have established a special framework for cooperation between Academia and Industry. We are working together with 9 companies on developing competitive products and services integrating nanomaterials and nanotechnologies. The solutions that are developed by joint team of researchers from our institute and partner companies include antistatic paints for solar PV and thermal panels for the reduction of dust depositions and securing their performances, anti-corrosion solutions for heat pump installations in coastal areas using sea water, catalytic filters for waste biomass boilers to facilitate the combustion of a wide range of waste biomass, nanofluid based oils for high performance ORC installations, hybrid solar panels, MEAs for urea fuel cells but also loS and IoT solutions for monitoring and system control. Putting in the forefront the industry, we try to improve their competitiveness and to build trust in cooperation with other players within the EU and worldwide.

In 2015, in New York, the UN General Assembly adopted the 2030 Agenda for Sustainable Development and the Sustainable Development Goals (SDGs), which include a dedicated goal on energy, SDG 7, calling to "ensure access to affordable, reliable, sustainable and modern energy for all". It is also important to mention the fact that Energy, lies at the heart of both the 2030 Agenda for Sustainable Development and the Paris Agreement on Climate Change.

A fundamental element to support the SDG 7, is to facilitate to all the citizens of the World the access to up-to-date knowledge which includes the Open Access to scientific research results. But, in a document of the European Commission [1] developed based on a comprehensive analysis of a large volume of scientific publications, it is mentioned that "Mostly due to current methods of capture and data malpractice, approximately $50 \%$ of all research data and experiments is considered not reproducible, and the vast majority (likely over $80 \%$ ) of data never makes it to a trusted and sustainable repository." In this respect, the Open Science movement including the aspects related to Open Access to the content of Scientific Journals, the Openness of the entire cycle of the scientific research process and the FAIR principles to publish data and metadata, may be also considered as a basic attempt for addressing the implementation of SDG 7.

This year, the Black Sea Universities Network established a pilot project on Open Science dedicated to the risks and vulnerabilities of using manufactured nanomaterials involving a group of researchers and with the support of the European Nanosafety Cluster and this process shall be further extended.

In the new paradigm of energy engineering, the symbiotic link between energy and information led to a fundamentally new approach on energy modeling. Recently, we started a new project under EU H2020 with a very valuable Europe wide consortium dedicated to the integration of waste heat streams from the industry in the District Heating systems. The approach that we are developing is to use massive data sets captured from a large variety of sensors and to develop Big Data and various other dedicated data mining tools for understanding the consumption characteristics of end-users, the matching with the available waste heat streams from local industries and with local resources of renewable energy. As a consequence, in the new paradigm, the optimization solutions are shifting from compliance with simple objective functions (as minimal cost or minimal impact) towards compliance with complex, dynamic, data driven solutions.

\section{Reference:}

[1] Realising the European Open Science Cloud, EC DG Research \& Innovation 2016 http://ec.europa.eu/research/openscience/pdf/realising the european open science cloud 2016.pdf\#vie $\underline{\mathrm{w}=\text { fit\&pagemode }=\text { none }}$

\section{About Professor Prof. Eden MAMUT}

Eden MAMUT is a Professor of Engineering Thermodynamics and Advanced Energy Systems at "Ovidius" University of Constanta, Romania, Director of the Institute for Nanotechnologies, Alternative Energy Sources, and Secretary General of the Black Sea Universities Network.

His field of research include: Advanced Energy Solutions based on nanomaterials and nanotechnologies, Multi scale thermo-fluid modeling, Analysis and optimization of complex energy systems, Renewable Energy Sources, Sustainable Transport Systems, Multi Criteria \& Multi Scale Methods on Sustainable Development.

Prof. Mamut is author and co-author of 95 papers, 12 books (as author or editor), 2 registered patents (Germany), 3 registered patents (Romania). 